\title{
TURISMO RURAL Y CRECIMIENTO INMOBILIARIO EN ESPACIOS DE MONTAÑA MEDIA. EL CASO DE LA SIERRA DE ARACENA ${ }^{1}$
}

\author{
Inmaculada MERCADO ALONSO - Alfonso FERNÁNDEZ TABALES - María \\ Victoria BASCARÁN ESTÉVEZ \\ Universidad de Sevilla
}

\author{
Recibido: $15 / 11 / 2011$ \\ Devuelto: 05/05/2012 \\ Aceptado: 02/07/2012
}

RESUMEN: Los espacios de montaña media en Andalucía, en especial aquéllos que cuentan con buena accesibilidad a zonas urbanas densas, han experimentado transformaciones importantes en los últimos años respecto a usos del suelo y modelo productivo. La crisis del mundo rural y de los sistemas agrícolas y ganaderos tradicionales, supuso un reto para la pervivencia de estos espacios, que paulatinamente se incorporaron a los procesos de producción terciaria difundidos desde los centros urbanos como vía alternativa. El paisaje ha sido el elemento esencial de atracción para la población de las ciudades: por un lado, se ha desarrollado la actividad turística, por otro, se ha producido un crecimiento inmobiliario para satisfacer la demanda de segunda residencia. Ambos fenómenos, que a veces aparecen relacionados, e incluso confundidos conceptualmente, son, sin embargo, opciones de uso del territorio diferentes que, dependiendo de su dinámica y dimensiones, pueden resultar incompatibles. Esta problemática es estudiada en el caso concreto de la Sierra de Aracena (Huelva), a través del análisis de datos estadísticos y de la comparación entre ortofotografías de diferentes momentos.

PALABRAS CLAVE: Turismo sostenible, Indicadores turísticos, Incidencia territorial sector construcción, Crecimiento urbanización, Mercado de la vivienda, Parques naturales.

\section{RURAL TOURISM AND HOUSING GROWTH IN MIDDLE MOUNTAIN SPACES. THE CASE OF SIERRA DE ARACENA MOUNTAIN RANGE}

ABSTRACT: The mid-mountain areas of Andalusia, in particular those which have a good connection to high-populated urban zones, have experienced significant transformations in recent years regarding land uses and production model. The crisis of rural land and farming and livestock systems was a challenge to the survival of these spaces, which were gradually incorporated to the tertiary production processes spread from urban centers as an alternative

\footnotetext{
${ }^{1}$ Este artículo es resultado de los trabajos realizados en el Proyecto de Investigación "Gobernanza territorial y conformación espacial de destinos turísticos. Discursos, procesos y dialécticas en diferentes escenarios" (Ref CSO 2010-20284), financiado por el Ministerio de Ciencia e Innovación de España. Plan Nacional de I+D+i 2008-2011.
} 
way. The landscape has been the essential element of attraction for the population of cities: on the one hand, tourism has been developed; on the other hand, there has been a growth in real estate to satisfy the demand for second homes. Both phenomena, which sometimes appear related, and even conceptually confused, are, however, different land use options that, depending on their dynamic and dimensions, may be incompatible. This problem is studied in the specific case of Sierra de Aracena (Huelva), through statistical analysis and comparison between orthophotos from different times.

KEY WORDS: Sustainable tourism, Tourist indicators, Territorial impact construction sector, Growth of urbanization, Housing market, Natural parks.

\section{INTRODUCCIÓN: LA DIALECTICA ENTRE USOS TURISTI- COS Y USOS INMOBILIARIOS EN ESPACIOS SERRANOS}

Una de las tendencias más relevantes y conocidas durante las últimas décadas en los espacios rurales españoles, ha sido su incorporación a las dinámicas de terciarización emanadas y difundidas desde las áreas urbanas. En estas dinámicas ocupan un papel protagonista las diversas actividades vinculadas al disfrute del ocio (PLAZA et AL., 2008), de forma que puede afirmarse que una de las líneas a través de las cuales se está produciendo la inserción de las áreas rurales en la cambiante sociedad actual, es su conversión en espacios de ocio para la población procedente de las aglomeraciones urbanas (CORRALIZA et AL, 2002; LóPEZ PAlOMEQUe, 2008; Silva, 2010).

Por efecto de esta tendencia se ha producido desde la década de los noventa del pasado siglo un rápido crecimiento de la planta de alojamientos en estos espacios, fundamentalmente en aquéllos con mayor calidad de recursos naturalísticos y paisajísticos, como es el caso del ámbito tratado en el presente artículo. Dicho crecimiento se ha experimentado tanto en oferta reglada (hoteles, campings, casas rurales sujetas a normativa, etc.), como en oferta de alojamiento no reglada (casas rurales ofertadas al mercado al margen de la legalidad) y segundas residencias de población foránea, con un claro predominio de la oferta no reglada y las residencias secundarias (FERNÁNDEZ TABALES et AL., 2007).

Es un asunto muy tratado en la literatura científica las complejas y a menudo conflictivas relaciones entre las segundas residencias y la oferta propiamente turística, que coexisten y compiten por el uso de los mismos espacios y recursos turísticos. La temática ha sido tratada lógicamente con mayor frecuencia en los ámbitos litorales (EXCELTUR, 2005; ÉQUIPE MIT, 2005; HUETE et AL., 2005; VERA, 2006; ANTÓN et AL., 2008; HUETE et AL., 2008; MAZÓN et AL., 2009), al ser en éstos donde la intensidad de ocupación y por ende de fricción es máxima; pero también existe una cierta tradición de tratamiento del problema en los espacios rurales y naturales (LÓPEZ PAlomeQue, 1984; Delgado et AL., 2005; Pulido, 2008; FernándeZ 
TABALES et AL., 2010; RIVERA, 2010). En conjunto, estos análisis coinciden en señalar los problemas de un excesivo sesgo residencialista en la inserción de las áreas rurales en la sociedad del ocio, en comparación con la oferta propiamente turística, tales como los mayores beneficios a largo plazo en rentas y empleos de ésta sobre la oferta residencial, el menor consumo por cada plaza de recursos como el suelo y el agua, los más amplios efectos inducidos sobre el tejido productivo local de la oferta comercial o, por último, las mejores posibilidades de ésta para la aplicación de estrategias de cualificación del destino. Frente a este conjunto de aspectos negativos sí cabe señalar como contrapartida el efecto que la construcción de segundas residencias ejerce para la revitalización de áreas serranas deprimidas, si bien sus mayores impactos positivos se agotan en el corto plazo, reduciéndose drásticamente una vez finaliza la construcción o rehabilitación del inmueble.

En este contexto general se introduce un factor esencial para la explicación de los procesos socioeconómicos y territoriales en la España reciente, como ha sido el explosivo crecimiento de la urbanización y la construcción en el ciclo expansivo transcurrido entre los últimos años del pasado siglo y la plasmación de la crisis a partir de 2007, ciclo que ha sido profusamente tratado por la literatura científica actual (GARCÍA-BELLIDO, 2005; NAREDO, 2006; RODRÍGUEZ LÓPEZ, 2009; GARCÍA-MONTALVO, 2009; OCAÑA, 2009; TALTAVUll, 2010; DoOL et AL., 2010; CUADRADO RourA, 2010; FERNÁNDEZ TABALES et AL., 2011; PAREJA-EASTWAY et AL., 2011). Este proceso, con denominaciones tan reveladoras como "boom inmobiliario" o "tsunami urbanístico", si bien ha presentado sus rasgos más intensos en las áreas litorales o grandes aglomeraciones urbanas, no se ha limitado a éstas y ha afectado asimismo, a menor escala cuantitativa pero con gran significación cualitativa, a los espacios rurales y naturales.

En el caso andaluz, y aplicando indicadores básicos sustentados en estadísticas oficiales, esta tendencia puede apreciarse y demostrarse en los datos ofrecidos en los CUADROS 1, 2 y 3. En éstos se expresa la intensidad del proceso en las comarcas que hemos caracterizado como serranas (a partir de una clasificación del territorio andaluz en comarcas adscritas a las cuatro grandes tipologías territoriales: litorales, urbanas, agrícolas interiores, y serranas $)^{2}$, destacando la elevada proporción de residencias secundarias y/o vacías (pero por tanto con potencial uso turístico) que refleja el dato del Índice de Función Residencial No Permanente ${ }^{3}$, nítidamente superior a las áreas

\footnotetext{
${ }^{2}$ Esta clasificación se ha derivado de un trabajo previo realizado por el equipo de investigación: "Sector de la construcción y desarrollo territorial en Andalucía" (en prensa).

${ }^{3}$ Como más tarde se ampliará, este indicador, resultante de relacionar las unidades catas-
} 
agrícolas interiores y aglomeraciones urbanas, y sólo superado, como es explicable dada la vinculación de éstas con los espacios de ocio, por las áreas litorales. Asimismo destacan poderosamente los datos relativos al mercado de trabajo, expresados en el porcentaje de empleos en el sector de la construcción sobre el total de empleos en el momento culminante del ciclo expansivo (2006), los cuales muestran la plena incorporación de las áreas rurales y serranas andaluzas al citado "boom inmobiliario" (si bien buena parte de estos empleados podían dirigirse a desarrollar su jornada laboral a ámbitos urbanos o litorales), tanto en el dato concreto del año 2006 como en la evolución desde 2000 a 2006, en la que la creciente orientación hacia la construcción de estas comarcas se hace aún más evidente, con un ritmo de incremento que supera al de las áreas urbanas y litorales.

Cuadro 1. Índice de Función Residencial No Permanente (2008).

Por grandes unidades territoriales.

\begin{tabular}{ll}
\hline \multicolumn{1}{c}{ Grandes unidades } & IFR \\
\hline Aglomeraciones urbanas & 0,43 \\
Áreas agrícolas interiores & 0,42 \\
Áreas litorales & 0,59 \\
Áreas serranas & 0,48
\end{tabular}

FUENTE: Dirección General del Catastro. Ministerio de Economía y Hacienda. SIMA. Sistema de Información Multiterritorial de Andalucía (IEA). Elaboración propia.

Cuadro 2. Empleo en la construcción sobre el total del empleo en el municipio (2006). Por grandes unidades territoriales.

\begin{tabular}{lc}
\multicolumn{1}{c}{ Grandes unidades } & Empleo construcción (\%) \\
\hline Aglomeraciones urbanas & 12 \\
Áreas agrícolas interiores & 15 \\
Áreas litorales & 18 \\
Áreas serranas & 12
\end{tabular}

FUENTE: Seguridad Social. Elaboración propia.

Así pues, se constata la extensión de la oleada constructora a las áreas serranas, en las que, dado el estancamiento demográfico generalizado de las mismas, ésta se ha orientado prioritariamente a la construcción o rehabilitación de viviendas para su uso como segundas residencias de recreo dirigidas a compradores residentes en aglomeraciones urbanas. Estos usos son frecuentemente confundidos con las actividades turísticas, sin embargo, entre

trales de uso residencial con la población empadronada, expresa la proporción de viviendas no usadas como primera residencia en un parque inmobiliario. 
ambos existen diferencias fundamentales en lo que se refiere a los agentes promotores y gestores de la oferta, los canales de comercialización empleados, y los segmentos de demanda a los que se dirigen; a lo que se añade, con carácter decisivo en lo relativo a los procesos analizados en este artículo, las implicaciones nítidamente diferenciadas que una y otra actividad presentan para los territorios-destinos. De forma que la actividad inmobilaria vinculada a la segunda residencia genera grandes beneficios a corto plazo para agentes privados (los derivados de la propia venta del inmueble) asociados a costes en el medio-largo plazo para el erario público (necesidad de dotar de equipamientos y servicios a nuevas superficies urbanizadas) (CRUZ VILLALÓN, 2001), frente a los beneficios más sostenidos y extendidos en el tiempo que la oferta comercial turística produce en los destinos, medidos en creación de rentas y empleos (EXCELTUR, 2005).

Cuadro 3. Evolución del número de empleados en la construcción $(2000-2006)$. Por grandes unidades territoriales.

\begin{tabular}{lc}
\hline \multicolumn{1}{c}{ Grandes unidades } & $\begin{array}{c}\text { Evolución empleados (2000 Base } \\
\text { cien) }\end{array}$ \\
\hline Aglomeraciones urbanas & 160 \\
Áreas agrícolas interiores & 218 \\
Áreas litorales & 167 \\
Áreas serranas & 179 \\
\hline
\end{tabular}

FUENTE: Seguridad Social. Elaboración propia.

A todo ello se suman los impactos que una excesiva o desordenada implantación de segundas residencias, en especial cuando éstas son construidas de nueva planta, producen sobre el paisaje tradicional de núcleos poblados o espacios agrícolas y forestales; deteriorando o banalizando un recurso, el paisaje, reconocido como el principal atractivo turístico de estas áreas (CONSEJERÍA TURISMO Y DePORTE, 2000; Silva et AL., 2008; PlazA, 2009), y mermando así, a menudo de forma irreversible, la calidad del espacio turístico en el que se basa la competitividad futura de estos destinos. En definitiva, aparece un complejo entramado de relaciones entre actividad turística, usos inmobiliarios y recursos territoriales en estos espacios serranos, que van a ser tratadas para el caso concreto de la Sierra de Aracena en los apartados subsiguientes.

\section{PRESENTACIÓN DE OBJETIVOS, HIPÓTESIS DE PARTIDA, METODOLOGÍA Y ÁMBITO SELECCIONADO.}

Como se ponía de relieve en el apartado anterior, a menudo existe una no- 
table confusión entre la actividad inmobiliaria dirigida a la producción de segundas residencias y la actividad turística propiamente dicha, confusión especialmente grave a la hora de determinar los factores causantes de los impactos negativos que experimentan los territorios devenidos en espacios turísticos. Uno de ellos es la degradación del paisaje, como consecuencia de la implantación de infraestructuras e instalaciones que atienden las necesidades de los turistas: alojamientos, aparcamientos, infraestructuras de acceso, equipamientos de interpretación, etc. Sin embargo, las mayores transformaciones de uso del suelo que se producen en estos espacios de desarrollo turístico, están generalmente protagonizadas por un fenómeno ajeno al turismo como actividad económica, el crecimiento inmobiliario.

La Sierra de Aracena (Huelva), declarada Parque Natural en su mayor parte en el año 1989, se incorpora durante las dos últimas décadas a los espacios rurales que se reconfiguran como espacios de ocio y recreación vinculados a cercanas áreas urbanas (área metropolitana de Sevilla especialmente). Ello ha significado, por un lado, un aumento de la oferta turística que se ha reflejado en el crecimiento del número de establecimientos y plazas de alojamiento, y por otro, en un crecimiento de la oferta de viviendas de segunda residencia, en el contexto generalizado de burbuja inmobiliaria en España, relacionado más con dinámicas especulativas y políticas de recaudación municipal, que con necesidades reales de vivienda. Ambas actividades han crecido, pero no de la misma forma ni con las mismas consecuencias.

En este contexto general, el artículo se plantea como objetivos de investigación los siguientes:

Analizar a través de datos estadísticos el desarrollo de la actividad turística en este espacio.

$\checkmark$ Cuantificar, mediante análisis estadísticos y la comparación de ortofotografías de diferentes momentos, el crecimiento de la urbanización y el parque de viviendas en el ámbito.

$\checkmark$ Relacionar ambos crecimientos, llegando a conclusiones sobre las orientaciones o tendencias predominantes en la reciente conformación del modelo territorial-turístico del área.

$\checkmark$ Plantear, a modo de discusión final, las repercusiones que pueden generarse para los recursos territoriales y turísticos, en especial el paisaje, de continuar las tendencias detectadas en el pasado reciente.

La hipótesis de partida en este trabajo es que el crecimiento inmobiliario, destinado a segundas residencias, que se ha producido en la Sierra de Arace- 
na en los últimos años es muy superior en volumen y repercusiones territoriales al correspondiente a establecimientos e instalaciones turísticas, pese al notable incremento de éstos. Dicha actividad inmobiliaria, dada la escala, morfología y localización de sus productos, deteriora el atractivo del espacio natural, en especial en lo referente al paisaje y, por tanto, reduce las potencialidades de desarrollo vinculadas propiamente a la actividad turística.

Como metodología se plantea hacer un análisis estadístico de la evolución de la oferta turística y de viviendas, estableciendo como indicadores, por una parte, el número de plazas turísticas y establecimientos, así como su evolución, características y distribución por municipios (lo que ofrece una medida de la utilización turística del territorio). Por otra, en lo referente a la oferta inmobiliaria, ante la imposibilidad de contar con fuentes homogéneas y actualizadas de viviendas construidas o iniciadas, se ha tratado estadísticamente el número de viviendas incorporadas al mercado como consecuencia de la aplicación de los Planes Andaluces de Vivienda y Suelo de diferentes años, especialmente poniendo en relación sus ritmos de crecimiento con la evolución demográfica de los distintos municipios.

Igualmente, se ha utilizado como indicador estadístico el Índice de Función Residencial No Permanente. Éste es resultado del cociente de las unidades catastrales de uso residencial de un municipio entre los habitantes de derecho del mismo. Al indicar la relación entre el volumen de viviendas y la población de derecho o permanente, muestra el peso proporcional alcanzado por las viviendas desocupadas o las de uso estacional (como segundas residencias de uso vacacional) (VERA, 2006). De esta forma, este indicador cubre las carencias de información derivadas de la periodicidad decenal de la principal fuente para analizar dicha cuestión, como es el Censo de Población y Vivienda.

El análisis estadístico se completa mediante el cálculo de la nueva superficie urbanizada destinada a uso residencial a través de la utilización de herramientas SIGs. Para ello se han seleccionado a modo de ejemplos significativos los tres municipios del ámbito con mayores crecimientos del suelo urbanizado en la etapa reciente: Aracena, Cortegana e Higuera de la Sierra. El análisis consiste en la comparación entre las ortofotografías de dos años relevantes: 1998 (al comienzo de la gran expansión inmobiliaria) y 2009 (cuando la crisis ha clausurado ya el ciclo expansivo), empleando como fuente las series de ortofotografías digitales en color publicadas por la Consejería de Medio Ambiente de la Junta de Andalucía. A partir de estas fuentes ortofotográficas de partida se ha realizado un proceso de digitalización y fotointerpretación, acompañado de revisión directa de resultados con trabajo de campo en los espacios estudiados, que ha dado como resultado la delimi- 
tación de los nuevos suelos urbanizados entre los años de referencia, la distinción en los mismos entre el uso residencial y otros usos, y su cuantificación superficial mediante la herramienta SIG.

La Sierra de Aracena es un espacio de montaña que se ubica en el extremo más occidental de Sierra Morena y corresponde administrativamente al norte de la provincia de Huelva (ver MAPA 1). Es un territorio poblado desde épocas remotas que, sin embargo, ha conservado una gran calidad ambiental y paisajística. Estos valores la han situado en una posición competitiva dentro de los espacios rurales incorporados a la función turística en Andalucía. A ello ha contribuido decisivamente su buena accesibilidad. Pese a tratarse de un espacio serrano relativamente excéntrico, la zona presenta tres ejes fundamentales de comunicaciones por carretera que, aunque unen puntos situados fuera del ámbito, le ofrecen una adecuada conectividad. Éstas son:

La vía N 435 entre Huelva capital y Extremadura (Badajoz) que atraviesa de norte a sur el centro de la Sierra.

$\checkmark$ La A-66 que conecta Sevilla y Extremadura (Ruta de la Plata), con orientación norte-sur, dispuesta tangencialmente, en el este.

Y, sobre todo, la N 433, que enlaza Sevilla (desde la A-66) y Portugal (Lisboa) y que con disposición este-oeste atraviesa el centro de la Sierra.

El fenómeno de crecimiento, tanto turístico como inmobiliario, no ha sido homogéneo en toda el área, y está bastante concentrado en el núcleo central de la misma, correspondiente a doce municipios, que son los seleccionados como ámbito del trabajo de investigación: Alájar, Aracena, Almonaster la Real, Castaño de Robledo, Cortegana, Fuenteheridos, Galaroza, Higuera de la Sierra, Linares de la Sierra, Jabugo, Santa Ana la Real y Los Marines. La selección se ha llevado a cabo teniendo en cuenta la relevancia cuantitativa demográfica y de la oferta turística, el carácter simbólico y representativo de los valores generales de la Sierra, y la continuidad espacial de los municipios incluidos en la muestra. Los doce municipios representan aproximadamente un 50\% de la población del ámbito del Parque Natural y cuentan en la actualidad con casi un $80 \%$ de la oferta de plazas turísticas. Están presentes en ellos los paisajes más representativos del entorno serrano (dehesa, castañar, riberas, ruedos agrarios y huertas). El criterio de contigüidad espacial ha determinado la inclusión de municipios de pequeño tamaño, que, sin embargo, pueden tener alto significado en relación a la temática planteada. 
Mapa 1. Localización del ámbito de estudio

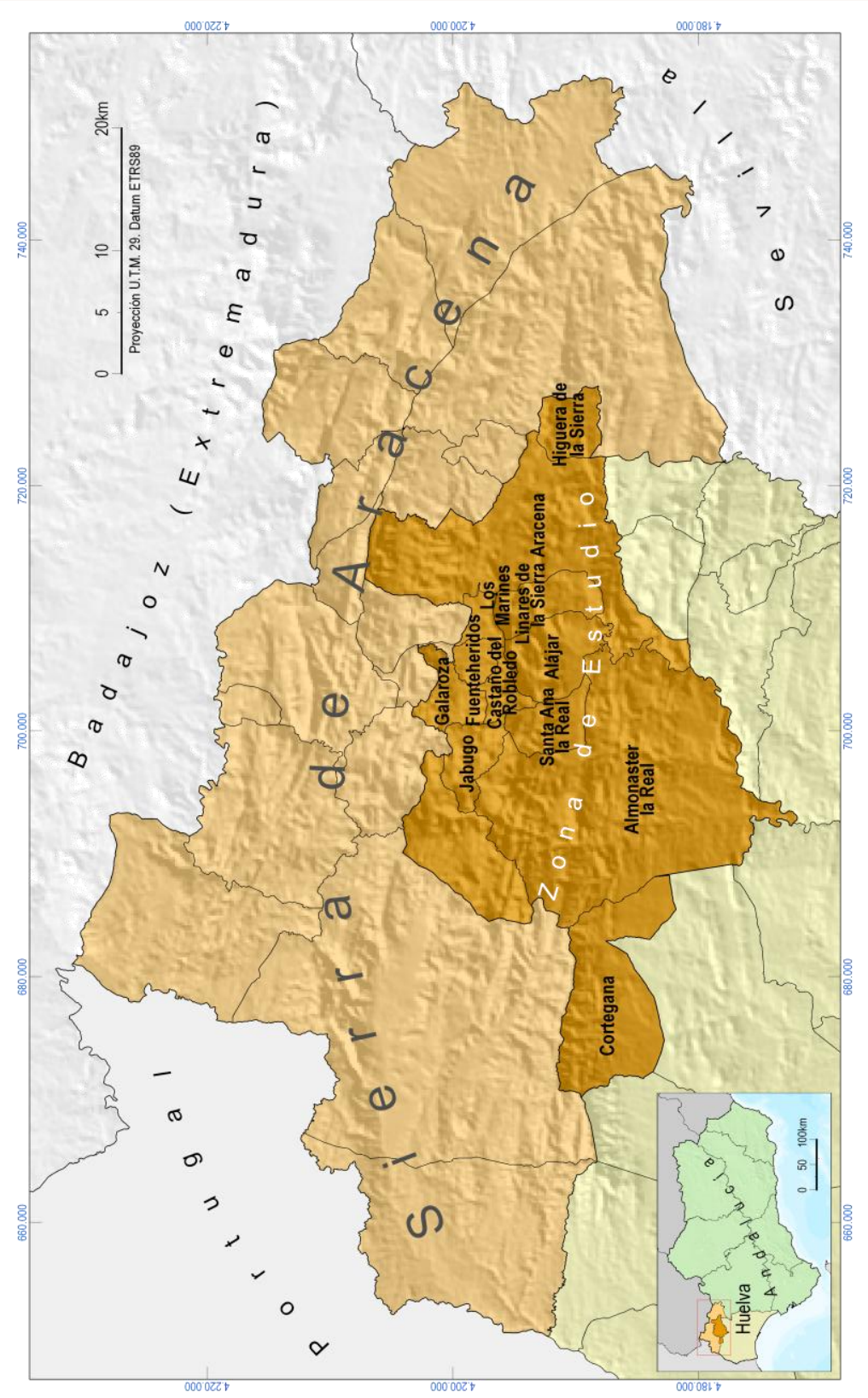

FuENTE: Ortofotografía digital 2009. Consejería de Medio Ambiente. Junta de Andalucía. Elaboración propia 


\section{LA EVOLUCIÓN DE LA OFERTA TURÍSTICA E INMOBI- LIARIA EN EL ÁMBITO DE ESTUDIO.}

\section{III.1. Análisis de la oferta turística.}

Pese a que el espacio serrano ha sido frecuentado por viajeros y residentes temporales desde el siglo XIX, el turismo moderno, traducido en una importante oferta de alojamiento y otras actividades complementarias que generen una actividad económica relevante, es bastante reciente. La declaración como Parque Natural (Ley 2/89, de 18 de julio, de Inventario de Espacios Naturales Protegidos de Andalucía) marca el inicio de esta nueva etapa, en un proceso de crecimiento que se acelera de forma notable en la primera década del siglo XXI.

El estudio de la evolución de las plazas de alojamiento reglado en el ámbito presenta algunas dificultades relacionadas con las limitaciones de las fuentes estadísticas. Por un lado, los registros que nos informan de la oferta existente en los momentos de inicio del crecimiento turístico en la Sierra de Aracena (primeros años de la década de los 90) pueden considerarse poco fiables. A partir del Decreto 15/1990, de 30 de enero, por el que se crea y regula la organización y funcionamiento del Registro de Establecimientos y Actividades Turísticas (REAT) existen datos aproximados de la oferta de alojamientos en la Comunidad Autónoma. Sin embargo, no es hasta la aprobación de la Ley 12/1999 de Turismo, cuando la existencia del Registro de Turismo de Andalucía (RTA), se considera un mandato legal y se establece la obligatoriedad de la inscripción del establecimiento y del servicio turístico, como requisito indispensable para el inicio de la actividad e incluso para poder acceder a las ayudas y subvenciones que la comunidad autónoma otorgue. Incluso desde esta fecha es necesario añadir algún tiempo de transición que fue necesario para que se produjera una inscripción real de los establecimientos que hasta entonces no lo estaban.

Así pues, se analiza la evolución del número de plazas regladas reconociendo las limitaciones de la fuente y estableciendo comparaciones y correcciones con otras fuentes, igualmente oficiales, como las guías de turismo publicadas por la Junta de Andalucía. Si bien este hecho puede distorsionar de alguna forma los resultados, se entiende que la debilidad de la oferta en esos años, en el contexto geográfico analizado, conduce a valorar dicha distorsión como poco relevante para los objetivos del estudio.

Por otro lado, sí es necesario destacar que, como en otras zonas turísticas, existe y ha existido una oferta no reglada de alojamiento, en la Sierra principalmente en casas particulares que se ofrecen en régimen de alquiler, cuyas 
dimensiones son muy difíciles de estimar, dado su carácter ilegal ${ }^{4}$. En el presente estudio no se ha considerado esta oferta como oferta turística propiamente dicha, ya que no responde a una dinámica empresarial y se canaliza mediante agencias inmobiliarias locales o contactos directos con los propietarios, lo que las mantiene, por otro lado, fuera de cualquier control de calidad. Sí aparecen contabilizadas en la oferta de alojamiento las Viviendas Turísticas de Alojamiento Rural (VTAR), cuya inscripción no es obligatoria en el Registro, pero que deben comunicar al mismo el inicio de actividad, por lo que pueden ser consideradas a efectos estadísticos.

Desde 1990 y hasta 2011 se ha producido un notable incremento de las plazas de alojamiento en los municipios del ámbito de estudio (GRÁFICO 1). En números absolutos se ha pasado de 217 a 2.892, lo que significa un incremento conjunto del $1.332,7 \%$. En la actualidad, ningún municipio del ámbito carece de plazas de alojamiento reglado, cuando a comienzos del periodo estudiado siete de ellos no tenían ninguna plaza. Estos datos ponen de manifiesto, por un lado, la intensidad y ritmo de creación de nuevas plazas de alojamiento, su distribución irregular en el territorio y su juventud, en la mayoría de los casos construidos o rehabilitados a partir del año 2000. Es destacable que, pese a la crisis, el sistema de alojamientos ha seguido creciendo a buen ritmo.

La máxima concentración de plazas se encuentra localizada en Aracena, que registra un $32,7 \%$ del total del área (GRÁfICO 2). Dos municipios, Aracena y Cortegana, concentran casi el 53\% de la oferta de plazas, un porcentaje importante de las cuales son plazas de hotel.

En cuanto a la distribución por modalidades de alojamiento (Gráfico 3), se aprecia un claro predominio de la casa rural y la vivienda turística de alojamiento rural (VTAR) que representan casi el 50\% de las plazas disponibles. El peso del alojamiento hotelero es, sin embargo, importante, con un 38\%, si bien es un rasgo más reciente en el sistema turístico local y se explica por la apertura de dos establecimientos a partir de 2007 con un número de plazas muy significativo (casi un $25 \%$ del total). La modalidad de camping, que representa el $8 \%$ de las plazas, responde a un solo establecimiento en el municipio de Almonaster la Real, en el núcleo de San Telmo, inscrito en 2009, que por las características propias de este tipo de

\footnotetext{
${ }^{4}$ Un reciente intento es el estudio de TURISME\&LEISURE (2008) La oferta de alojamiento turístico no reglada en España. Comisión de Turismo del Consejo Superior de Cámaras de Comercio de España.
} 
alojamiento y su situación geográfica tiene escasa repercusión en el territorio.

Gráfico 1. Evolución de las plazas de alojamiento en el ámbito

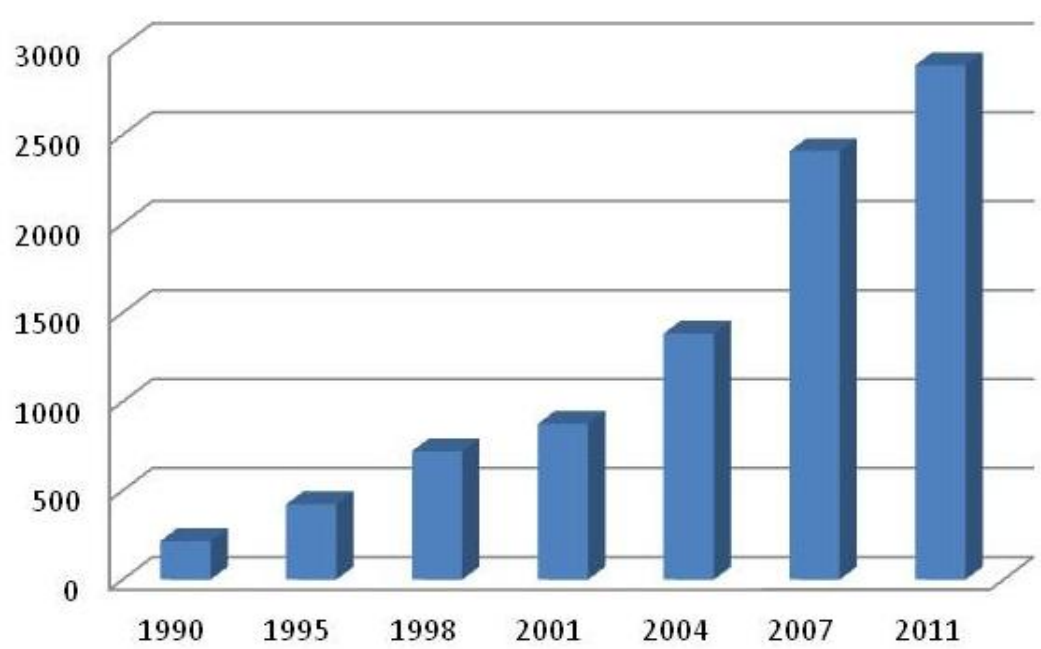

FUENTE: REAT y RTA 1990-2011 y Guias de alojamientos turísticos. Junta de Andalucía. Elaboración propia.

Gráfico 2. Distribución porcentual de plazas de alojamiento por municipio, 2011

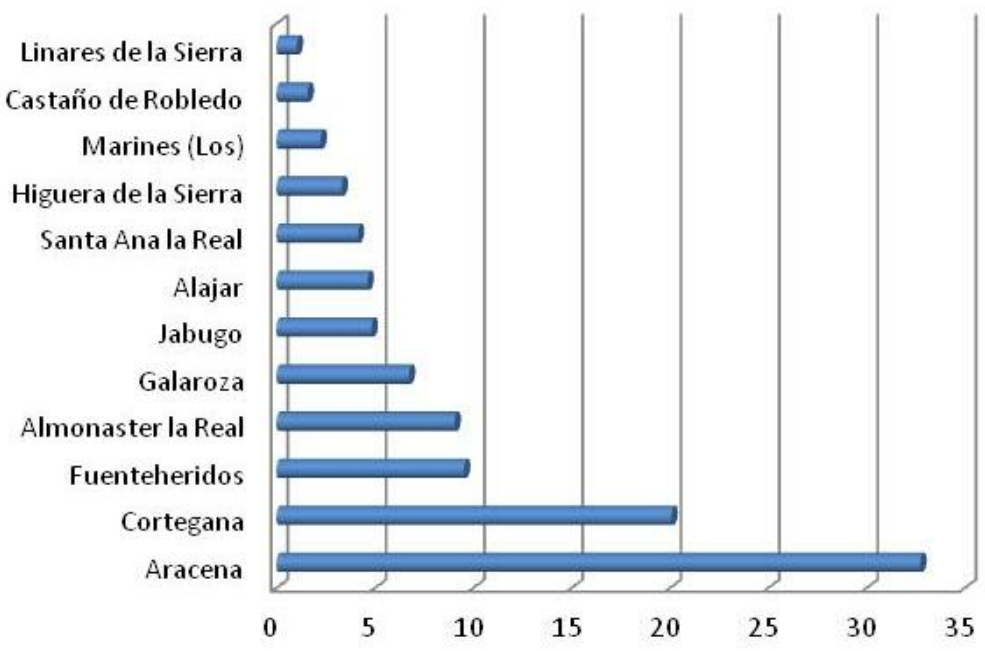

FUENTE: RTA 2012. Elaboración propia. 
Gráfico 3. Distribución porcentual de plazas por tipo de alojamiento, 2011

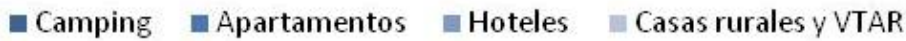

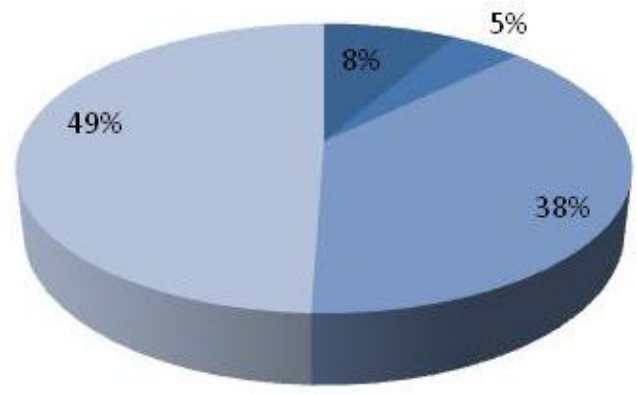

FUENTE: RTA 2011. Elaboración propia.

Este volumen de plazas de alojamiento turístico se concreta en la existencia de 288 establecimientos, si bien este dato debe interpretarse como unidades de explotación y no como empresas, ya que existen en el registro incripciones con número diferenciado para distintas casas que pertenecen a un mismo complejo o dueño. Sólo 22 de ellos son alojamientos hoteleros, que concentran una gran cantidad de plazas, lo que da una idea del pequeño tamaño de las explotaciones en los casos del resto de las modalidades y su dispersión empresarial.

La mayor parte de los establecimientos caracterizados como casas rurales se encuentran situados en el entorno natural, forman parte de fincas rústicas o de construcciones que tuvieron otros usos en el pasado (molinos, estaciones de ferrocarril...). Son pocas las que se encuentran situadas en los núcleos urbanos. En ninguno de los casos se trata de construcciones de nueva planta, si bien todas ellas han sufrido importantes remodelaciones y adaptaciones a la función de alojamiento. Se trata mayoritariamente de edificaciones que han conservado la tipología, los materiales contructivos propios de la Sierra y han cuidado la adaptación al entorno, respetando las normas estrictas que se recogen en el Plan de Uso y Gestión del Parque Natural. Los establecimientos, que cuentan en todos los casos para su promoción y comercialización con página web propia, utilizan como primer reclamo de su atractivo precisamente la integración en el paisaje (ya sea natural o construido) y la posibilidad con la que cuenta el visitante de vivir la experiencia turística de la cultura serrana empezando por el alojamiento.

En cuanto a los hoteles la situación es mucho más variada (CUADRO 4). En esta modalidad la mayoría de los establecimientos se encuentran situados en 
los cascos urbanos o cercanos a las vías de comunicación, muy pocos en el entorno natural. Veinte de estos establecimientos son de nueva construcción, con una gran variedad de tipologías, en algunos casos no relacionadas con las tradicionales edificaciones de la Sierra. Los que se encuentran situados en el entorno natural adoptan, en la mayoría de los casos, la forma de complejos turísticos, con actividades complementarias, utilizando antiguas construcciones asociadas a las labores del campo (cuadras, almacenes, molinos...).

Cuadro 4. Caracterización de la oferta de alojamientos hoteleros en el ámbito (número de establecimientos).

\begin{tabular}{cccccccc}
\hline$a$ & $b$ & $c$ & $d$ & $e$ & $f$ & $g$ & $h$ \\
\hline 2 & 16 & 4 & 14 & 8 & 2 & 4 & 16 \\
\hline
\end{tabular}

a, Ubicación carretera; b, Ubicación urbana; c, Ubicación entorno natural; d, Nueva construcción; e, Rehabilitación; f, Categoría 4*; g, Categoría 3*; h, Categoría 2* y menos FUENTE: Junta de Andalucía. RTA 2011.

La oferta de alojamiento turístico en el ámbito de estudio, considerando todas las modalidades, es, por tanto, bastante reciente y presenta, en general, poco impacto paisajístico, siendo en su mayoría, en especial las Casas Rurales, resultado de la rehabilitación de edificaciones, tanto de inmuebles en los cascos urbanos como situados en fincas rústicas con antiguos usos agroganaderos. Esta tendencia se explica por dos tipos de factores:

a) Una normativa estricta de edificación que afecta al territorio declarado Parque Natural, especialmente la que se refiere a la rehabilitación de viviendas existentes, que ha sido respetada por los nuevos establecimientos. Los instrumentos de gestión del Parque Natural (Plan de Ordenación de Recursos Naturales y Plan Rector de Uso y Gestión) establecen criterios claros sobre las características constructivas y de integración en el paisaje de las edificaciones que deben recogerse en los planeamientos municipales. Así, establece que los planeamientos urbanísticos deberán definir características edificatorias, fundamentalmente en lo que se refiere al concepto de arquitectura tradicional según las peculiaridades de la zona, con el fin de conservar la arquitectura popular; tanto en los núcleos de población como en las edificaciones en suelo no urbanizable, y que estas últimas se vinculen a la explotación agraria, ya sean viviendas del agricultor o almacenes, estableciéndose limitaciones superficiales a la citada explotación. 
b) Una concepción del propio alojamiento como factor de atracción para el turismo rural. La valoración del paisaje natural o histórico es la primera causa de elección del destino para el turista en espacio rural, pero es creciente la tendencia a considerar el alojamiento en sí mismo, y los factores relacionados con la calidad, adecuación al entorno, sostenibilidad, etc., como un factor de decisión, convirtiendo lo que se clasificaba tradicionalmente como infraestructura en un verdadero recurso turístico (CANOVAS et AL., 2005).

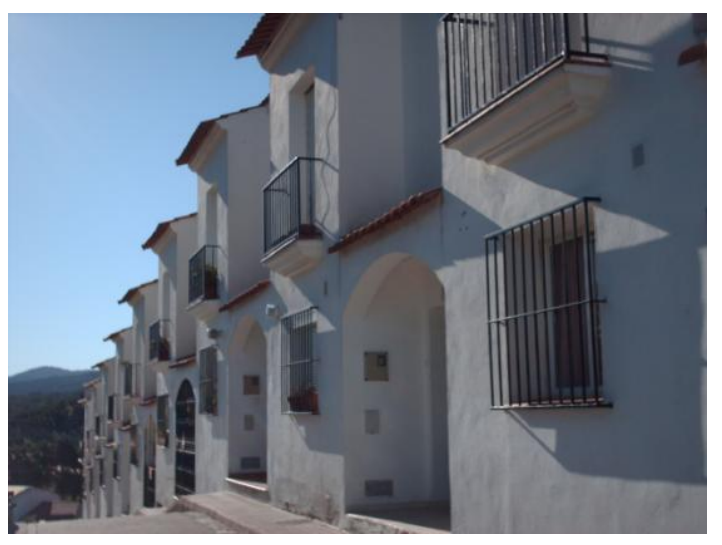
tradicional en la Sierra, constituida por viajeros por motivos de trabajo, de paso, y con escasa motivación recreativa, en el primer caso, o bien turistas que buscan precios más asequibles.

\section{III.2. La oferta inmobiliaria.}

Como ya se ha señalado en el apartado introductorio, el conjunto del Estado ha experimentado un notable proceso urbanizador entre 1990 y $2008^{5}$. Este fenómeno no solo ha afectado a los núcleos urbanos y a la franja litoral, sino que ha tenido presencia en el mundo rural, especialmente en áreas cercanas o accesibles a grandes áreas metropolitanas, como es el caso de la Sierra de Aracena. Pese a las restricciones que puede suponer la presencia de una figura de protección como el Parque Natural, se constatará a continuación que no ha sido suficiente impedimento para que se incrementen notoriamente las cifras de vivienda de nueva planta, en contradicción con una situación demográfica estancada o en regresión, siendo igualmente insuficien-

\footnotetext{
${ }^{5}$ Según fuentes del Banco de España, en 2008 existían 26.230.579 viviendas en España, lo que representaba 1,55 viviendas por familia, una de las tasas más altas del mundo.
} 
tes dichas medidas para garantizar que las nuevas construcciones respeten los valores históricos y paisajísticos serranos.

Estudiar la vivienda en la escala municipal presenta dificultades debido a la limitación de las fuentes estadísticas (PALACIOS, 2008). El último censo de vivienda data de 2001, momento en el que se acelera el boom constructivo en todo el territorio del Estado; además ese censo presenta muchas dudas sobre su ejecución y resultados ${ }^{6}$. Igualmente, tampoco están disponibles datos homogéneos y actualizados de viviendas iniciadas o construidas por municipio. Así pues, la primera década del siglo XXI hay que estudiarla a través de fuentes de carácter indirecto. En este caso, se han utilizado los balances de ejecución de los Planes Concertados de Vivienda y Suelo de la Junta de Andalucía (referidos a actuaciones protegidas de alquiler, venta, rehabilitación y suelo); el Índice de Función Residencial No Permanente (IFRNP); y el incremento de la superficie urbanizada de los núcleos principales del ámbito, a través de una comparación de ortofotografías de diferentes momentos (1998 y 2009) y su cuantificación mediante SIG.

Por lo que respecta al primer indicador indirecto, el Censo de viviendas de 2001 arrojaba una cifra para el ámbito de estudio de 11.953. Los datos de ejecución de los sucesivos Planes de vivienda de la Junta de Andalucía indican que entre 1999 y 2010 estos planes habían afectado en el ámbito a 2.588 viviendas, incluyendo en esta cifra tanto la construcción de viviendas de nueva planta como la rehabilitación de inmuebles preexistentes degradados (asimismo a estas cifras habría que añadir pequeños montantes de viviendas debidas totalmente a la iniciativa privada, muy escasas en la Sierra; en todo caso con la fuente utilizada puede partirse de unos mínimos reales, útiles para realizar aproximaciones cualitativas y comparaciones fiables estadísticamente entre espacios diferenciados). Aceptando así que no es posible determinar cuántas de las actuaciones de construcción o rehabilitación corresponden a viviendas ya censadas en 2001, la cifra significaría, en cualquier caso, un incremento de unidades residenciales incorporadas al mercado inmobiliario, rehabilitadas o de nueva construcción, del 21,7\% (GRÁFICO 4), que se sitúa por debajo de la media provincial $(23,3 \%)$, pero por encima de la media andaluza (19,5\%). Algunos municipios presentan situaciones de crecimiento muy significativas, que están por encima, incluso, de la media provincial.

\footnotetext{
${ }^{6}$ La comparación de los censos de viviendas de los años 1991 y 2001 con datos de viviendas iniciadas durante ese periodo pone de relieve algunas contradicciones, ya que mientras las cifras censales muestran reducciones o pérdida de viviendas en algunos de los municipios del ámbito (Galaroza, Linares de la Sierra), el análisis de las viviendas iniciadas indicaría una estabilización e incluso un incremento. Estas discrepancias plantean dudas razonables sobre la exactitud de los datos procedentes del censo de 2001.
} 
Son los casos de Aracena (34,2\%), Cortegana (25,4\%), Los Marines $(27,1 \%)$, Santa Ana la Real $(26,8 \%)$, y rozando la media provincial Castaño de Robledo $(22,6 \%)$.

Gráfico 4. Incremento de unidades residenciales incorporadas al mercado inmobiliario respecto al Censo 2001 (\%). Planes de vivienda y suelo de la Junta de Andalucía.

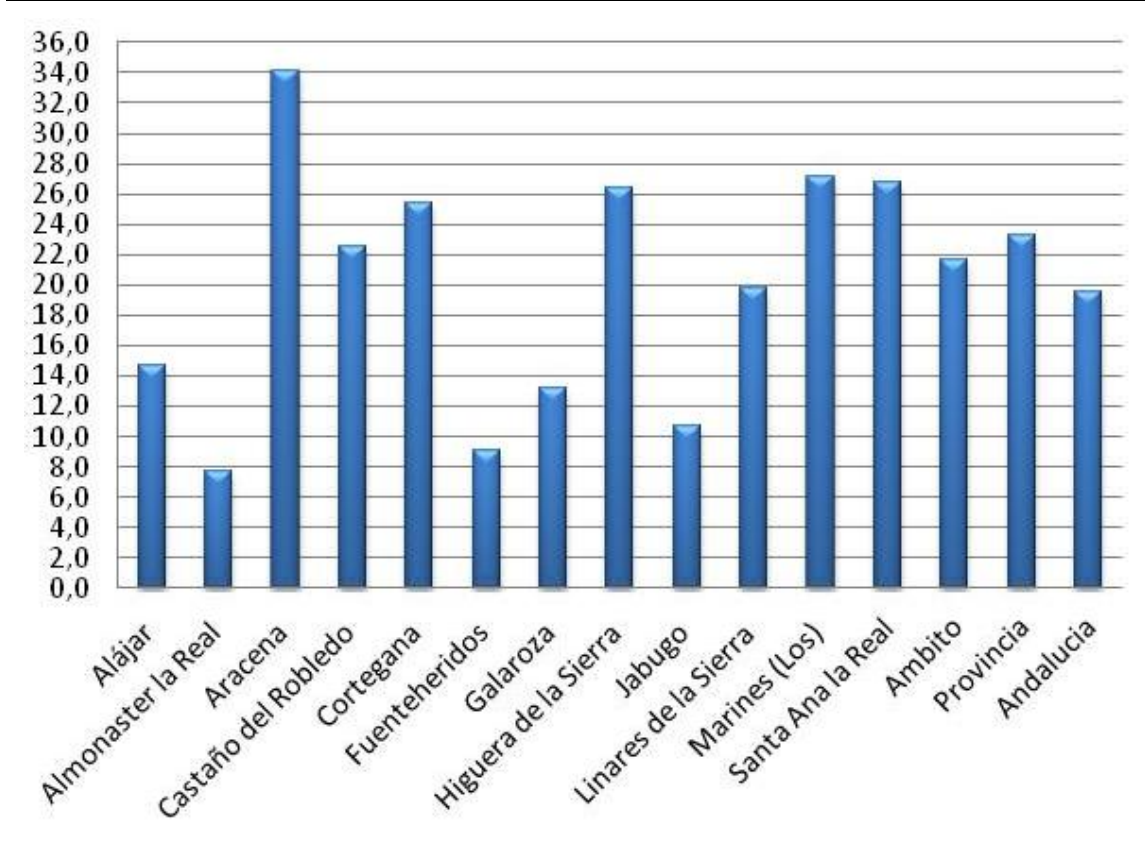

FUENTE: Censo de vivienda de 2001. Balances de ejecución municipal del III Plan Andaluz de Vivienda y Suelo (1999-2003), IV Plan Andaluz de Vivienda y suelo (2003-2007) y Plan Concertado de vivienda y suelo 2008-2012 (años 2008-2009-2010). Elaboración propia.

Los balances de ejecución de los planes públicos no indican cuántas de estas viviendas tienen carácter secundario o cuántas permanecen vacías, no obstante, permiten poner en relación las cifras (que pueden estimarse como una hipótesis mínima respecto a la situación real) de crecimiento de vivienda respecto a la dinámica demográfica del ámbito, lo que permitiría aproximarse a la demanda de primera vivienda frente a las actuaciones que tienen como mercado la segunda residencia, permanente o temporal, o la inversión especulativa. Desde 1991 la población del ámbito permanece estancada, con un crecimiento en promedio del $1,6 \%$, y siete de los municipios implicados con decrecimiento. El número total de personas en las que se ha incrementado la población del ámbito es de 201 (CUADRO 5), que, considerando un 
promedio para el mismo de 2,86 personas por hogar ${ }^{7}$, significaría una necesidad neta de 71 viviendas. Parece evidente que no existe proporción entre una dinámica demográfica que puede considerarse regresiva y un crecimiento inmobiliario que desde el punto de vista de la demanda objetiva de la población empadronada se puede estimar como sobredimensionado.

Cuadro 5. Evolución de la población del ámbito de estudio (número de efectivos).

\begin{tabular}{lrrrr}
\hline & Población & Población & Población & Incremento \\
& 1991 & 2001 & 2010 & $91 / 10$ \\
\hline Alájar & 836 & 775 & 821 & -15 \\
Almonaster la Real & 2.109 & 1.947 & 1.860 & -249 \\
Aracena & 6.503 & 6.831 & 7.228 & 725 \\
Castaño del Robledo & 195 & 194 & 214 & 19 \\
Cortegana & 5.243 & 5.007 & 5.039 & -204 \\
Fuenteheridos & 650 & 641 & 606 & -44 \\
Galaroza & 1.603 & 1.618 & 1.606 & 3 \\
Higuera de la Sierra & 1.330 & 1.284 & 1.361 & 31 \\
Jabugo & 2.510 & 2.550 & 2.473 & -37 \\
Linares de la Sierra & 283 & 290 & 308 & 25 \\
Marines (Los) & 352 & 325 & 320 & -32 \\
Santa Ana la Real & 505 & 474 & 484 & -21 \\
\hline Ámbito & 22.119 & 21.936 & 22.320 & 201 \\
\hline
\end{tabular}

FUENTE: INE. Censo de población 1991-2001 y Padrón de Población de 2010.

Esta débil relación entre la evolución de la población de derecho y el crecimiento de la vivienda puede corroborarse con el análisis del ya mencionado Índice de Función Residencial No Permanente. La magnitud pone en relación las unidades catastrales de uso residencial con la población de derecho. Los municipios que se acercan al valor cero muestran situaciones donde las unidades residenciales corresponden fundamentalmente a población permanente, mientras que los que se alejan de cero mostrarían que una buena parte de dichas unidades es de uso vacacional o están vacías (pero por tanto con potencial uso turístico). El resultado para 2010 (GRÁFICO 5) muestra que sólo dos municipios (Aracena y Jabugo) tienen un índice inferior al provincial, aunque en todos los casos es superior al de Andalucía. El resto de los municipios están por encima de estos promedios, cinco de ellos superando el 0,80 , lo que los equipara, e incluso supera, a municipios costeros de la provincia de Huelva con fuerte presencia turística, como Cartaya $(0,68)$, Lepe $(0,73)$ o Isla Cristina $(0,81)$.

\footnotetext{
${ }^{7}$ El dato se ha obtenido a partir del Censo de Vivienda de 2001, dividiendo el número de hogares habitados por la población del área.
} 
Gráfico 5. Índice de función residencial no permanente, 2010

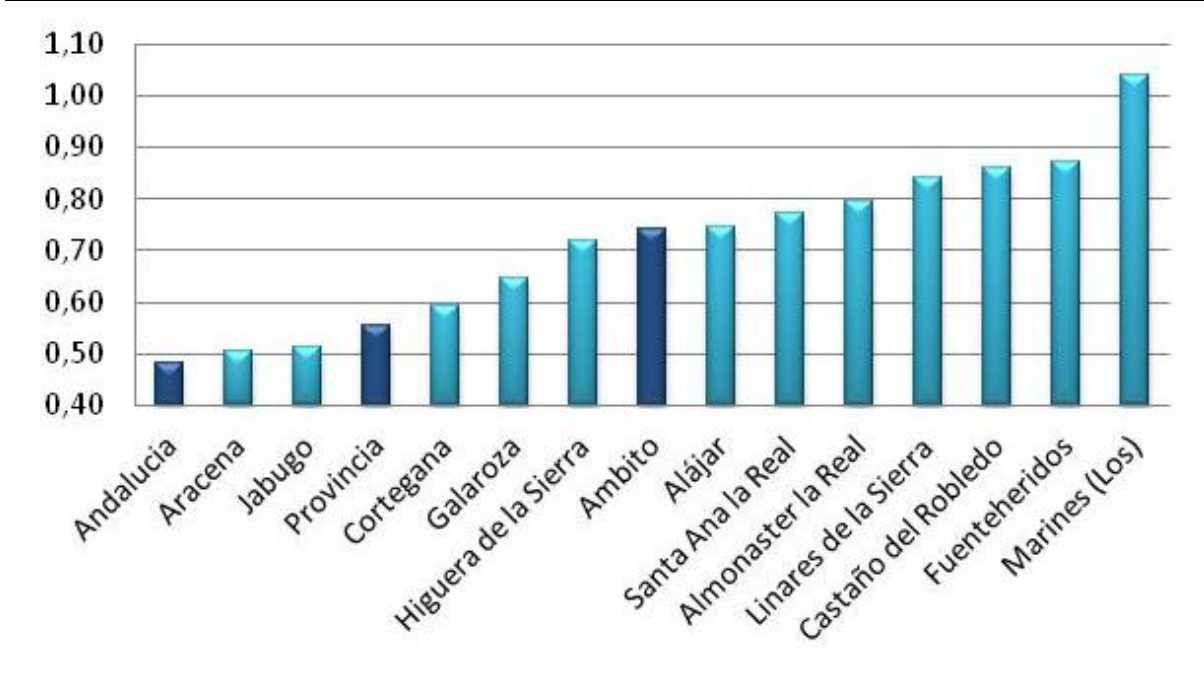

FuENTE: Catastro 2010. Padrón 2010. Elaboración propia.

El IFRNP tiene la limitación de no discriminar lo que pueden ser viviendas con función de segunda residencia o vacacionales respecto a los inmuebles vacíos. Las características socioeconómicas y demográficas de los municipios del ámbito pueden hacer pensar que los elevados índices registrados se refieren a municipios con gran cantidad de viviendas vacías, fruto fundamentalmente de la despoblación y la regresión demográfica. Sin embargo, el análisis de las cifras de incremento de unidades residenciales incorporadas al mercado inmobiliario, que se estudiaban anteriormente, así como una comparativa del mismo índice sólo cuatro años antes, puede resultar clarificador.

Algunos de los municipios que aparecen en el gráfico anterior con los valores más altos del IFRNP, como Los Marines, Castaño de Robledo o Linares de la Sierra, coinciden con aquéllos que presentan notables incrementos del número de unidades residenciales incorporadas al mercado inmobiliario entre 2001 y 2010, que en los tres casos superan el $19 \%$. Aunque algunas de estas viviendas ya estuviesen censadas en 2001, se ha producido en ellas una intervención que las sitúa de hecho en el mercado. Esto permite concluir que existen viviendas construidas recientemente, bien de nueva planta, bien rehabilitadas, que han contribuido a aumentar la funcion residencial no permanente de estos municipios.

Por otro lado, prácticamente todos los municipios del ámbito han incrementado dicho Índice entre 2006 y 2010, como se refleja en el GRÁFICO 
6. En el corto periodo de tiempo contemplado no parece que el factor que explique el incremento pueda relacionarse con el despoblamiento y el consiguiente aumento de inmuebles vacíos, sino que tendría relación con un incremento de viviendas para fines de segunda residencia o vacacionales. Hay municipios con crecimientos sobresalientes como Higuera de la Sierra o Cortegana, y nuevamente, Linares de la Sierra y Castaño de Robledo.

Gráfico 6. Índice de función residencial no permanente. Comparativa 2006-2010

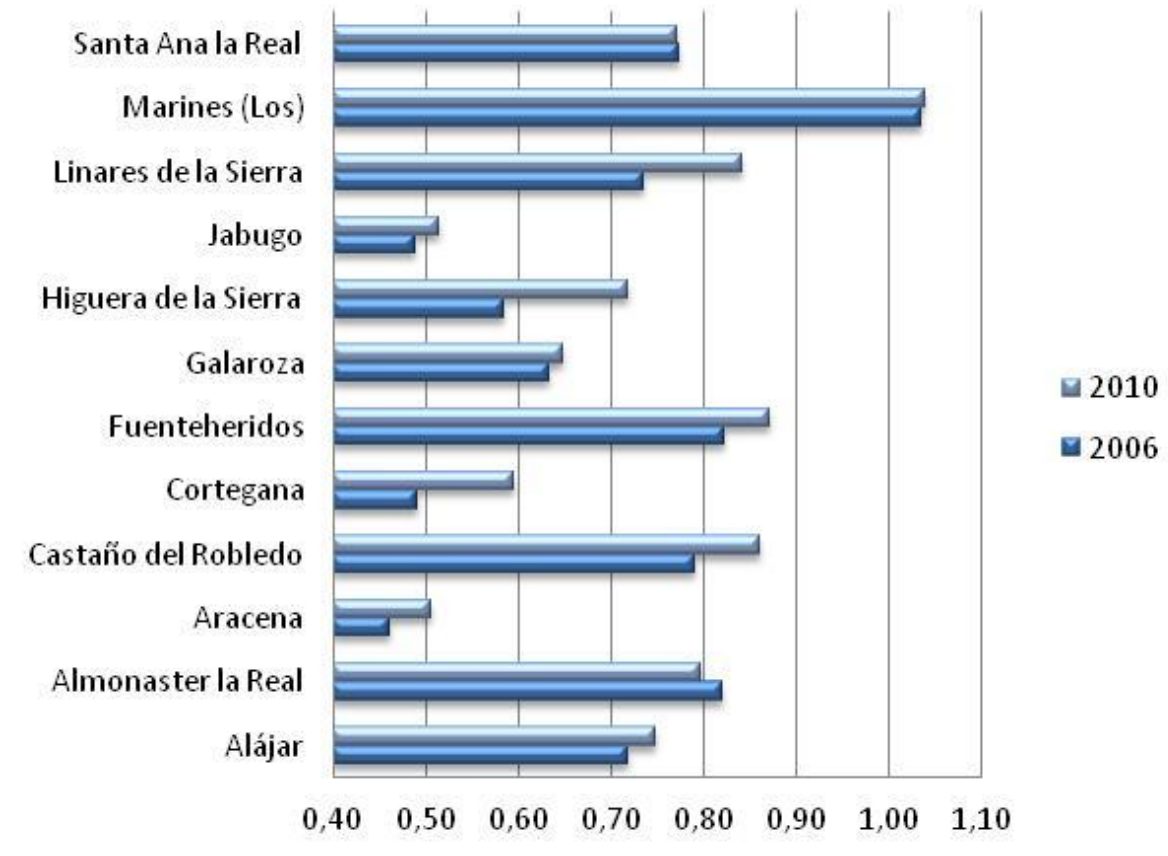

FUENTE: Catastro 2010. Padrón 2010. Elaboración propia.

Por último, otra fuente considerada para conocer el crecimiento inmobiliario de los municipios del ámbito ha sido la comparación de las ortofotografías digitales de 1998 y 2009. Para realizar este trabajo se han elegido tres municipios por su tamaño en superficie y población, Aracena, Cortegana e Higuera de la Sierra, considerando las actuaciones en los núcleos poblados, incluidos, en el caso de Aracena, las entidades menores de Valdezufre, La Umbría y Jabuguillo. En el caso de Cortegana, cuyo término municipal está dividido en dos, y separado por un área que pertenece a los municipios de Almonaster la Real y Aroche, sólo se ha considerado el núcleo principal, en la zona norte del municipio, ya que son poco 
significativas, en la escala considerada, las modificiaciones producidas en las numerosas entidades menores dispersas por el resto del municipio.

Las ortofotografías ponen de manifiesto que se han producido crecimientos muy significativos en el suelo incorporado a los procesos de urbanización en los núcleos estudiados, en un intervalo de tiempo de poco más de una década, especialmente en los casos de Aracena (más de un 39\% sobre el núcleo original) e Higuera de la Sierra (21,5\%). Ha sido menor el crecimiento que se ha producido en Cortegana (5\%). Estas cifras incluyen cualquier uso de suelo urbanizado no presente en la ortofotografía de 1998. Un análisis más en detalle permite comprobar que la mayoría de estos crecimientos tienen como finalidad la construcción de viviendas o uso residencial. En los tres casos los usos residenciales superarían al conjunto de los otros usos (industriales, comerciales, turísticos, equipamientos públicos, etc.) y suponen en torno a un $75 \%$ del total de los nuevos suelos incorporados al proceso urbanizador. Existe, pues, una clara opción por el crecimiento del suelo de uso residencial, ya que es mucho menor el incremento que se ha producido para usos productivos o para infraestructuras y servicios públicos.

Cuadro 6. Crecimiento de suelo urbanizado1998-2009 (en ha).

\begin{tabular}{lrrrrr}
\hline \multicolumn{1}{c}{$a$} & $b$ & $c$ & $d$ & $e$ & $f$ \\
\hline Aracena & 160,6 & 62,9 & 39,17 & 49,2 & 74,11 \\
Cortegana & 108,4 & 5,6 & 5,15 & 4,3 & 76,61 \\
Higuera de la Sierra & 38,2 & 8,2 & 21,53 & 6,2 & 75,13 \\
\hline
\end{tabular}

a, Municipio; a, Urbanizado en 1998; c, Crecimiento urbanizado 1998-2009; d, Incremento $\%$; e, Crecimiento residencial 1998-2009; $f$, \% incremento para residencial

FUENTE: Ortofotografías digitales 1998 y 2009. Junta de Andalucía.Y elaboración propia.

El análisis tanto de las ortofotografías como de los mapas elaborados a partir de ellas permite, igualmente, una consideración sobre la mayoritaria ubicación de los nuevos suelos residenciales en los bordes urbanos, es decir, que se ha producido un crecimiento neto del suelo urbano consolidado y las actuaciones de nueva construcción de viviendas no se han limitado a suelos disponibles intraurbanos. El espacio reconocible en las ortofotografías de 1998, con nuevos usos ya en 2009 , se identificaba con pequeñas huertas, espacios de transición hacia las dehesas circundantes, zona de almacenamiento de aperos o de estabulación de ganado, etc. El tipo de edificación que se ha desarrollado en estos suelos responde mayoritariamente al modo de viviendas seriadas, con predominio de la unifamiliar adosada. 
En el caso de Aracena (MAPA 2), cuyo crecimiento de suelo urbanizado puede considerarse especialmente notable, cabría señalar que el que corresponde a las entidades menores (Jabuguillo, Valdezufre) tiene, por el tamaño reducido de las mismas, un impacto porcentual y visual, si cabe, mayor que en el caso del núcleo principal, aunque pueda parecer inapreciable como consecuencia de la escala utilizada en la representación. No se trata de un fenómeno cuantitativamente destacable, en cuanto al número de viviendas o la superficie ocupada, pero el impacto paisajístico es considerable al ubicarse en un contexto de núcleos de pequeño tamaño y tipologías constructivas muy tradicionales. Esto podría aplicarse a otros núcleos que se encuentran diseminados por la Sierra, que presentan pequeñas intervenciones en cuanto a la cantidad de lo transformado, pero cuya suma y orientación tendencial pone de manifiesto un proceso de cambio necesitado de mayor investigación en detalle de cara al futuro.

En el caso de Higuera de la Sierra (MAPA 3), se han producido crecimientos importantes en las inmediaciones de la N-433, principal eje de acceso a la Sierra de Aracena desde la aglomeración urbana de Sevilla, y en un área considerable en la zona noroeste del núcleo, en sustitución de antiguos usos productivos primarios. El suelo productivo de nueva creación se ha ubicado en un polígono situado al sur del núcleo, que es contiguo a nuevos usos residenciales.

Por último, el caso de Cortegana (MAPA 4), situada en el interior de la Sierra, más alejada de la influencia de los flujos urbanos y con más dificultades de acceso, no ha experimentado crecimientos tan intensos. Si bien en su planeamiento urbanístico aprobado se prevén importantes crecimientos de los usos residenciales, actualmente detenidos por el impacto de la crisis económica.

Finalmente, desde el punto de vista del impacto paisajístico que estas nuevas actuaciones han generado en el ámbito de estudio, existen, como ocurría en el caso de la oferta turística, dos realidades bien diferenciadas.

Por un lado, las actuaciones de rehabilitación que se han producido dentro de los cascos urbanos consolidados, sujetas a normativas municipales de protección vinculadas a su carácter de Conjuntos Histórico Artísticos (nueve de los municipios del ámbito) y contempladas en las distintas determinaciones de los instrumentos de gestión del Parque Natural (PORN-PRUG), que ya se mencionaron más arriba, han propiciado en general una buena integración en el entorno construido tradicional de la sierra. Destacan las limitaciones en la altura y el respeto a la estructura constructiva de los antiguos edificios, y, so- 
Mapa 2. Crecimiento de suelo urbanizado en Aracena 1998-2009.

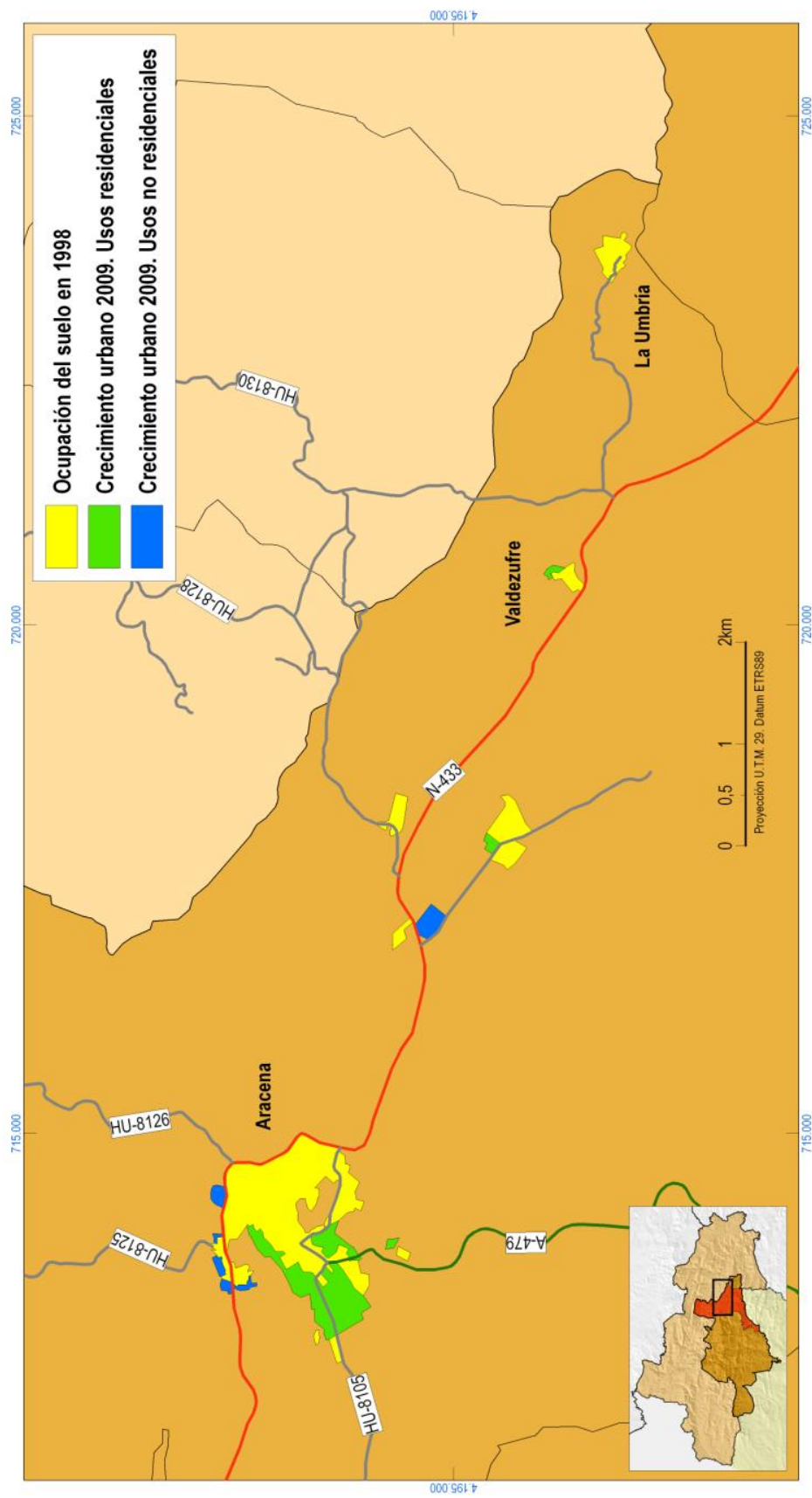

FUENTE: Ortofotografías 1998-2009. Junta de Andalucía. Elaboración propia 
Mapa 3. Crecimiento de suelo urbanizado en Higuera de la Sierra 1998-2009.

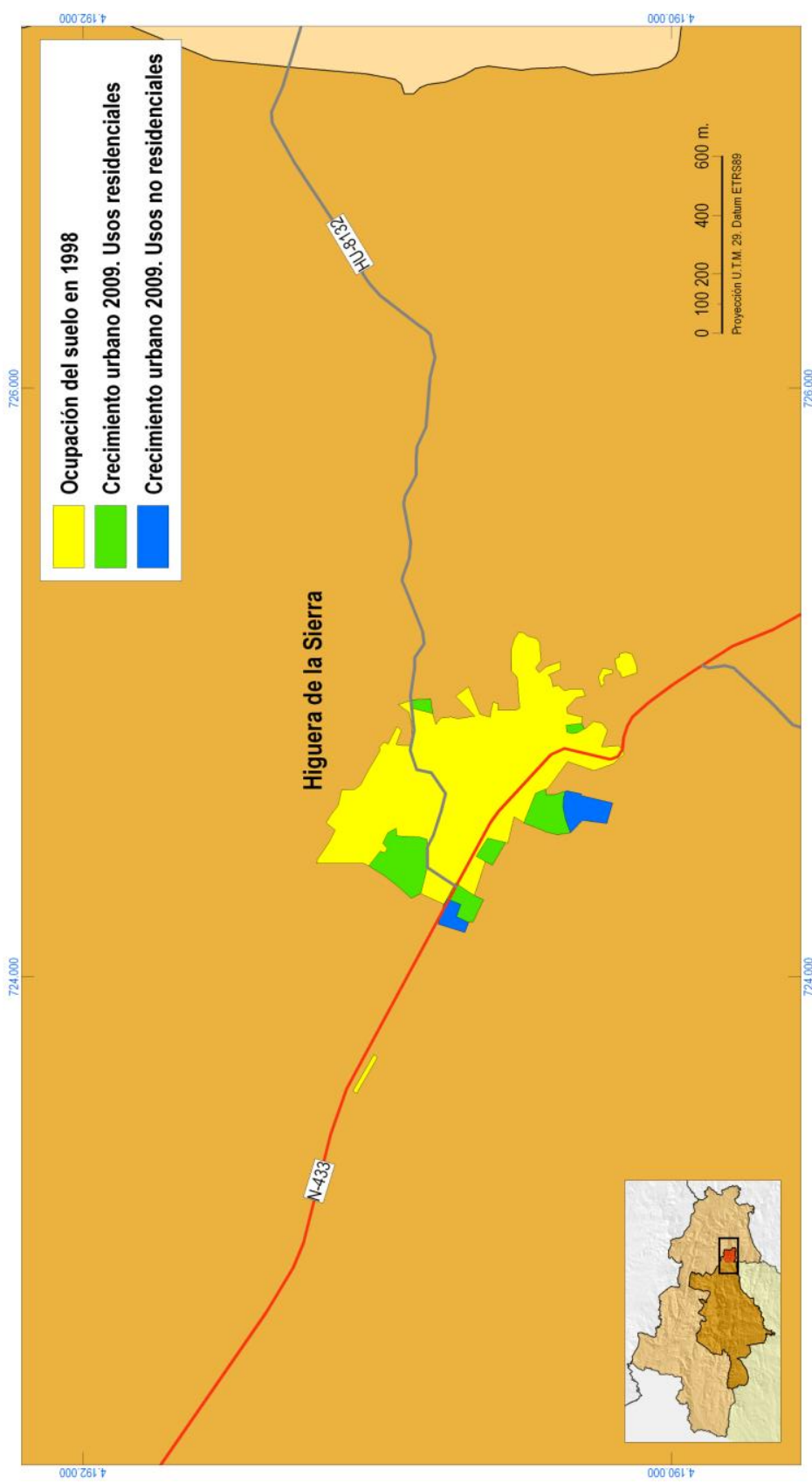

FUENTE: Ortofotografías 1998-2009. Junta de Andalucía. Elaboración propia 
Mapa 4. Crecimiento de suelo urbanizado en Cortegana 1998-2009.

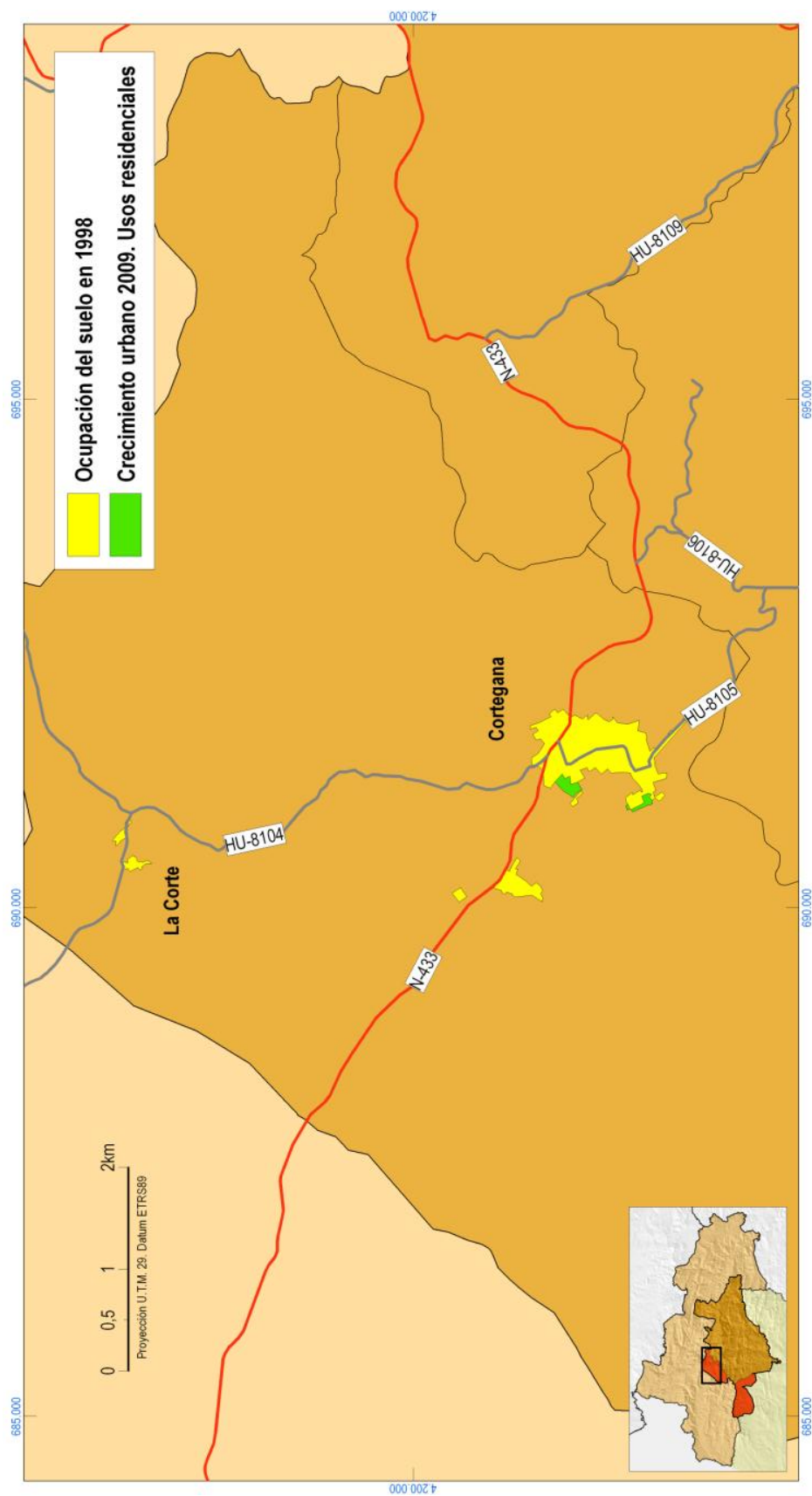

FUENTE: Ortofotografías 1998-2009. Junta de Andalucía. Elaboración propia 
bre todo, la utilización de materiales tradicionales: piedra, cal, forjados en hierro, vigas de madera, etc.

Sin embargo, las urbanizaciones desarrolladas en suelos incorporados como urbanizables en las nuevas figuras de planeamiento municipal, responden a modelos más estandarizados, tanto en su morfología como en los materiales utilizados. Se trata de urbanizaciones en las que los inmuebles se agrupan generalmente como adosados, con estructuras convencionales de vivienda urbana y materiales con predominio de prefabricados, aluminio, teja industrial etc. La localización de estas viviendas seriadas suele coincidir con zonas externas de los núcleos urbanos consolidados, en los polígonos que han sido identificados como nuevas zonas urbanizadas en las ortofotografías utilizadas, y que ocupan antiguos ruedos agrarios de policultivos y usos múltiples agroganaderos, cuya estructura de pequeñas parcelas ha facilitado el acceso a los mercados inmobiliarios y acelerado el proceso urbanizador.

\section{CONCLUSIONES.}

En un contexto de crisis estructural del sector primario, despoblación del campo y fuerte terciarización de la economía andaluza, numerosos espacios rurales y naturales de interior se han incorporado al mercado como bienes de consumo para los habitantes de las ciudades, bien en la modalidad de turismo ocasional, bien como segunda residencia más o menos permanente. La Sierra de Aracena, gracias a una cierta tradición de lugar de descanso de la población urbana de Sevilla desde principios del siglo XX, y a sus indudables valores ambientales y paisajísticos, se ha posicionado de forma satisfactoria y asumido este nuevo papel de espacio recreativo, siendo actualmente uno de los parques naturales más visitados de Andalucía ${ }^{8}$. De la misma forma, ha existido un dinámico mercado de viviendas producto tanto de la rehabilitación como de la nueva construcción.

Esta dinámica ha tenido especial incidencia en el corazón de la Sierra, en un grupo de municipios que, por su ubicación, cuentan con una buena conectividad con las áreas de demanda. Se concentran en este área los paisajes más bellos y mejor conservados de la zona, al situarse en ella las cotas más altas y los valles más profundos, y contar con elementos significativos para la valoración de su patrimonio por parte del visitante: presencia de agua y

\footnotetext{
${ }^{8}$ No existen datos municipalizados de visitantes en el ámbito de estudio. Los estudios para la redacción del Plan de Ordenación Territorial de la Sierra de Aracena estimaron, con fuentes del Parque Natural y de las principales atracciones turísticas, así como con una estimación indirecta de la ocupación hotelera, que el número de visitas al parque se situaría entre los 100.000 y los 150.000 visitantes anuales.
} 
bosques de ribera, ecosistemas transformados de dehesa y castañar, hitos cársticos como la Cueva de las Maravillas y la Peña de Arias Montano, conjuntos histórico artísticos, gran concentración de equipamientos del Parque Natural (Centro de Interpretación, senderos, miradores...) etc.

El crecimiento de la actividad turística se refleja en el aumento de la oferta de plazas de alojamiento que se ha producido en el ámbito desde 1990, especialmente intenso en la primera década del siglo XXI. El parque de plazas turísticas es, pues, joven, y ha mejorado en calidad con la apertura de algunos establecimientos de categoría superior.

Por otra parte, su impacto territorial en el ámbito estudiado resulta bastante limitado. En primer lugar, porque, pese a representar el $90 \%$ de las plazas existentes en toda la Sierra, rondando las 2.000 , el número de es-

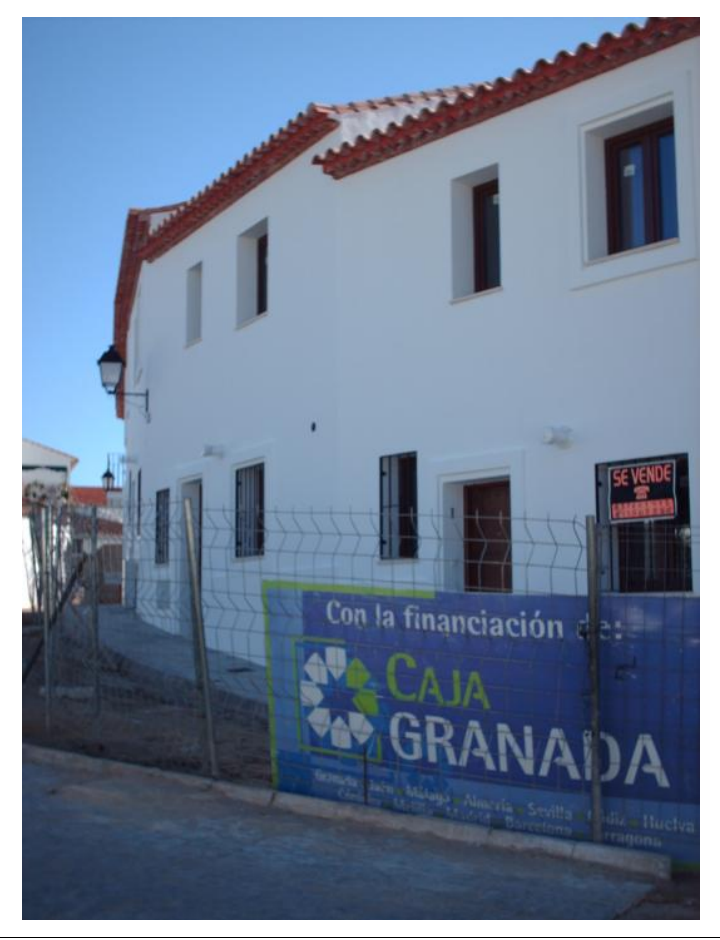
tablecimientos sólo supera ligeramente el centenar, la mayoría de ellos casas rurales rehabilitadas. Esto significa una ocupación mínima de suelo, que se une a la dispersión en pequeñas unidades de explotación y al predominio de tipologías edificatorias tradicionales. En segundo lugar, porque su propia estrategia de diferenciación se basa en la identificación con los valores ambientales y paisajísticos del entorno. El atractivo turístico es precisamente la naturaleza y el patrimonio rural de unos pueblos bien conservados en su estructura original durante siglos. Las agresiones al paisaje y a la morfología urbana de los mismos rebajarían la posición competitiva del destino porque serían contradictorias con las expectativas de la demanda actual, orientada a modelos basados en criterios de sostenibilidad, autenticidad, singularidad... $\mathrm{y}$, por tanto, contrarias a los intereses del sector turístico local.

Más controvertida se presenta la dinámica de crecimiento inmobiliario. Las distintas fuentes utilizadas, tanto estadísticas como ortofotográficas, además de la observación directa de campo, ponen de manifiesto que la Sie- 
rra de Aracena no ha escapado a la dinámica de boom inmobiliario de muchos otros espacios turísticos en Andalucía. La construcción de nuevas viviendas no está sustentada en el crecimiento demográfico de la población empadronada, puesto que las cifras de los últimos veinte años arrojan resultados de estancamiento e incluso de regresión, que no explican intervenciones de las dimensiones que se han puesto de manifiesto en la investigación. En la realidad de un espacio rural demográficamente débil, que se hayan incorporado al mercado un mínimo estimado de casi 2.600 viviendas en los últimos diez años, o que el crecimiento en esta década del suelo urbanizado en el principal núcleo del ámbito (Aracena) alcance casi un 40\% sobre el suelo urbano preexistente, significa que existe otro tipo de motivaciones más allá de las necesidades básicas de la población. Según el mismo modelo estudiado para otros espacios turísticos, especialmente litorales, la construcción de vivienda nueva o rehabilitación de viviendas en desuso o infraviviendas se ha producido como respuesta a la demanda de segunda residencia, bien como objeto de consumo, bien como inversión especulativa, como han señalado diferentes autores (VERA, 2006; OCAÑA, 2009; TALTAVULL, 2010; FERNÁNDEZ TABALES et AL., 2011); asimismo, a esto se le une la necesidad de financiación de las entidades locales, que han optado generalizadamente por la vía de potenciar la extensión de la urbanización como fórmula para aumentar el nivel de sus ingresos.

Las repercusiones en el territorio de este tipo de actuaciones urbanísticas se concretan en nuevos espacios de crecimiento de los núcleos urbanos consolidados, ubicados generalmente en zonas vulnerables de transición entre lo construido y los ruedos agrarios tradicionales, importando modelos estandarizados de construcción que suponen una ruptura con la imagen de entorno rural, y una morfología más acorde con áreas metropolitanas o litorales.

Los procesos, y el volumen de sus resultados, no son todavía determinantes, puesto que se trata de actuaciones puntuales y que responden a un espacio geográfico y temporal limitado. Sin embargo, es preocupante el ritmo constatado en los últimos años que, de no haber sido frenado a partir de 2007 por efecto de la crisis económica, sí hubiese desencadenado procesos de transformación irreversibles.

Estos procesos tienen una repercusión negativa para las expectativas de desarrollo del turismo rural y de naturaleza que se puedan dar en el ámbito. La opción por un modelo turístico competitivo, sostenible, basado en el patrimonio territorial de la Sierra de Aracena, es incompatible con un crecimiento inmobiliario basado en la demanda de segunda residencia o la inversión especulativa. Esta última opción, cuya intensidad en el área hasta el impacto de la crisis ha mostrado el análisis previo, supone asumir un coste de 
oportunidad que debe ser evaluado de cara al futuro desde el punto de vista económico, social y territorial; evaluación de la que deberán surgir las estrategias para la inserción de este espacio serrano en el nuevo escenario de relaciones entre el mundo rural y el urbano a medio y largo plazo.

\section{BIBLIOGRAFÍA.}

ANTON Clavé, S.; GonZÁlez Reverte, F. (coords.) (2008): A propósito del turismo. La construcción social del espacio turístico. Barcelona, U.O.C.

Canoves Valiente, G.; HerRera Jimenez, L.; Villarino Perez, M. (2005): «Turismo rural en España: paisajes y usuarios, nuevos usos y nuevas visiones». En Cuadernos de Turismo, $\mathrm{n}^{\circ}$ 15, 63-76.

Consejería De Turismo y Deporte (2000): Plan SENDA: Desarrollo de un sistema turístico sostenible y competitivo integrado en el espacio rural andaluz. Sevilla, Consejería de Turismo y Deporte. Junta de Andalucía.

CORRALIZA, J.A. (2002): Los parques naturales en España: conservación y disfrute. Madrid, Fundación Alonso Martín Escudero.

CRUZ Villalón, J. (2001) «¿Quiere ser Andalucía la segunda residencia de Europa?» Diario El País, 6 de marzo de 2001.

CUADRADO RouRA, J.R (dir.) (2010): El sector de la construcción en España. Madrid. Colegio Libre de Eméritos.

Delgado Viñas, C.; Gil De Arriba, C.; Hortelano Mínguez, L.A.; Plaza GUTIERREZ, J.I. (2005): «Terciarización turística y difusión urbana en un espacio rural de montaña: la segunda residencia en el sector central de la Cordillera Cantábrica». En Turismo Residencial y cambio social: nuevas perspectivas teóricas y empíricas. (MAZON MARTINEZ, T.M.-ALEDO TUR, A. coords.) 157-172.

Dool, K., HaffNer, M. (2010): Housing Statistics in the European Union. The Hague: Ministry of the Interior and Kingdom Relations. OTB Research Institute for the Built Environment, Delft University of Technology.

EQUIPE MiT (2005): Turismes 2. Moments de Lieux. París.

EXCELTUR (2005): Impactos sobre el entorno, la economía y el empleo de los distintos modelos de desarrollo turístico del litoral mediterráneo español, Baleares y Canarias. Madrid, Exceltur. Alianza por la Excelencia Turística.

FernándeZ TABALES, A., MeNDOZA, A. (2007) «La actividad turística en el territorio andaluz. Establecimiento de indicadores, distribución y evolución de los mismos». Boletín de la Asociación de Geógrafos Españoles. $\mathrm{n}^{\circ}$ 44. 117-146.

FERNÁNDEZ TABALES, A., SANTOS PAVÓN, E. (2010) «Turismo y parques naturales en Andalucía tras veinte años desde su declaración. Análisis estadístico, tipología de parques y problemática de la situación actual». Anales de Geografía de la Universidad Complutense. vol. 30, $\mathrm{n}^{\circ} 1.29-54$

FERNÁNDEZ TABALES, A., CRUZ MAZO, E. (2011): «Territorio y actividad constructiva: del "tsunami" a la crisis. Factores explicativos y propuesta de indicadores a escala municipal en Andalucía», Boletín de la Asociación de Geógrafos Españoles. $\mathrm{n}^{\circ} 56.79-110$. 
GARCÍA-BELLIDO, J. (2005): «Por una liberalización del paradigma urbanístico español (III): El tsunami urbanístico que arrasará el territorio». Ciudad y Territorio. Estudios territoriales, $\mathrm{n}^{\circ} 144,273-288$.

GARCíA-Montalvo, J. (2009): «Financiación inmobiliaria, burbuja crediticia y crisis financiera. Lecciones a partir de la recesión de 2008-09». Papeles de Economía Española, $\mathrm{n}^{\mathrm{o}} 122,66-87$.

Huete Nieves, R.; MAZON MARTinez, T.M. (2005): «Turismo residencial en el litoral alicantino: los casos de Denia, Altea, Benidorm, Santa Pola y Torrevieja», en Turismo residencial y cambio social: nuevas perspectivas teóricas y empíricas (MAZON MARTINEZ-ALEDO TUR, coords.) 105-138.

Huete Nieves, R.; MAntecon, A.; MAZOn Martinez, T.M. (2008): «¿De qué hablamos cuando hablamos de turismo residencial?» Cuadernos de Turismo. $\mathrm{n}^{\mathrm{o}} 22$. 101-121.

LOPEZ PALOMEQUE, F. (1984): «La apropiación del espacio de montaña como resultado del proceso de creación de espacio de ocio: el caso del Valle de Arán (Pirineos-España)». En: Aportación Española al XXV Congreso Geográfico Internacional, 205-219.

LOPEZ PALOMEQUE, F. (2008): «Delimitación conceptual y tipologías del turismo rural», en El Turismo Rural: estructura económica y configuración territorial en España. (PULIDO FERNANDEZ, J.I., coord.) 21-51. Madrid. Ed. Síntesis.

Mazon Martinez, T.M.; Huete Nieves, R.; Mantecon, A.; Jorge Sierra, M.E. (2009): «Legitimación y crisis en la urbanización de las regiones turísticas mediterráneas». En Turismo, urbanización y estilos de vida: las nuevas formas de movilidad residencial (MAZÓn MARTínEZ, T.M.; HuETE NIEVES, R.; MANTECón, A., coords.), 399-412. Barcelona. Ed. Icaria.

NAREDO, J. (2006): «Mitos inmobiliarios de nuestro tiempo». El Ecologista, nº46 2005/2006.

OCAÑA, C. (2009): «Urbanización y vivienda, negocio financiero y conflicto social» en Territorios, sociedades y políticas. Sevilla, Universidad Pablo de Olavide y Asociación de Geógrafos Españoles. 349-368.

PAlACiOS GARCíA, A.J. (2008): «Fuentes estadísticas sobre la vivienda en España: un obstáculo para el diseño de la política de vivienda», en X Coloquio Internacional de Geocrítica: Diez años de cambios en el Mundo, en la Geografía y en las Ciencias Sociales, 1999-2008. Universidad de Barcelona.

PAREJA EASTway, M.; SÁnchez MartíneZ, Ma T. (2011): «El mercado de vivienda en España: la necesidad de nuevas propuestas» en Acceso a la Vivienda en un contexto de crisis.31-52. Edisofer, Madrid.

Plaza Gutiérrez, J.L.; Martín Giménez, M.I.; Hortelano Mínguez, L.A.; FERNÁNDEZ ÁlVAREZ, R. (2008): «Desarrollo territorial y cambios en las montañas interiores (factores, tendencias e iniciativas). Contraste y estudios de caso». Polígonos: revista de geografía. no $18,155-191$.

PlAZA GuTIÉRREZ, J.I. (2009): «Nuevos territorios y nuevos desarrollos en las áreas rurales: conservación, patrimonio, biodiversidad, paisaje». Observatorio Medioambiental. $\mathrm{n}^{\mathrm{o}} 12,9-14$.

PULIDO FERNÁNDEZ, J.I. (2008): «Gestión turística activa y desarrollo económico en los parques naturales andaluces. Una propuesta de revisión desde el análisis de 
posicionamiento de sus actuales gestores». Revista de Estudios Regionales. $\mathrm{n}^{\circ}$ 81, 171-203.

RiVERA MATEOS, M. (2010): Turismo activo en la naturaleza y espacios de ocio en Andalucía: aspectos territoriales, políticas públicas y estrategias de planificación. Sevilla. Consejería de Turismo y Deporte. Junta de Andalucía.

RODRÍGUEZ LÓPEZ, J. (2009): «La crisis de los mercados inmobiliario e hipotecario. Factores explicativos», Papeles de Economía Española, $\mathrm{n}^{\circ} 122,236-253$.

Silva PÉrez, R., Fernández Salinas, V. (2008): «El patrimonio y el territorio como activos para el desarrollo desde la perspectiva del ocio y del turismo». Investigaciones Geográficas. no 46. 69-88.

SILVA PÉREZ, R (2010): «Multifuncionalidad agraria y territorio: algunas reflexiones y propuestas de análisis» Eure: revista latinoamericana de estudios urbano regionales. $\mathrm{n}^{\mathrm{o}}$ 109. 5-33.

TAlTAVUll De LA PAZ, P. (2010): «El sector de la construcción y el mercado de la vivienda: del valle a la recuperación». Revista Economistas, año 28, nº123, 8899

VERA, F. (2006): «El auge de la función residencial en destinos turísticos del litoral mediterráneo: entre el crecimiento y la renovación». Papers de Turisme, no 37 $38,95-114$. 